\title{
PERBEDAAN PENYERAPAN AIR KE DALAM RESIN KOMPOSIT MIKROHIBRID DAN NANOHIBRID SETELAH DIRENDAM DI DALAM SALIVA BUATAN
}

\author{
(DIFFERENCES OF WATER ABSORPTION INTO MICRO AND NANOHYBRID \\ COMPOSITE RESINS AFTER IMMERSED IN ARTIFICIAL SALIVA)
}

\author{
Kholidina Imanda Harahap*, Harry Agusnar**, Sumadhi Sastrodihardjo**** \\ *Program Pendidikan Magister Kedokteran Gigi FKG USU \\ **Departemen Kimia FMIPA USU \\ ***Departemen Ilmu Material dan Teknologi Kedokteran Gigi FKG USU \\ E-mail: drgdina@yahoo.com \\ Jl. Alumni No.2 Kampus USU Medan
}

\begin{abstract}
Composite resin as a restorative material will contact with saliva continuously and will absorb water in the mouth. Water absorption will decrease physical and mechanical properties and leach the elements of composite resin causes shortening shelf life and toxicity will occur. The aim of this study was to compare the amount, depth and rate of water absorption between microhybrid and nanohybrid composite resin and identifying the elements after immersed in artificial saliva. Microhybrid and nanohybrid composite resins were used in this study. Samples were made in tablet shape with $15 \mathrm{~mm}$ in diameter and $1 \mathrm{~mm}$ in thickness and cured with visible blue light. This study was performed by immersing the samples in artificial saliva for 2, 4, 6, and 8 hours. Amount of water absorption was calculated by using the changes on weight of samples and depth of water absorption were measured by using micrograph microscope. The rate of water absorption was calculated by comparing depth of water absorption and immersion time. The elements of samples were investigated by using SEM-EDX. The result showed that the amount of water absorption of microhybrid composite resin was 2.69, 5.71, 5.88, and 5.96\% whereas for nanohybrid was 5.34, 3.76, 3.09 and $2.83 \%$. The measuring depth of water absorption microhybrid composite resins was 3054.98, 6125.42, 8529.94, and 8930.01 $\mu \mathrm{m}$ whereas for nanohybrid was 7830,77, $6941.29,6844.67$ and $6120.53 \mu \mathrm{m}$. The calculating of rate water absorption in microhybrid composite resin was 1527,45 , 1531.36, 1421.66 and $1116.18 \mu \mathrm{m} / \mathrm{hr}$ whereas for nanohybrid was 3915.39, 1735.32, 1140, 78 and $761.32 \mu \mathrm{m} / \mathrm{hr}$. Statistical analysis of three variables showed the significant differences between both materials $(\mathrm{p}<0.05)$. The result of investigation showed decrease and increase some elements of composite resin. In conclusion, the amount and depth of water absorption on microhybrid was higher than nanohybrid composite resin whereas for rate of absorption of both resins were decreased
\end{abstract}

Key words: composite resin, microhybrid, nanohybrid, water absorption

\begin{abstract}
Abstrak
Resin komposit sebagai bahan restorasi di dalam mulut akan selalu berkontak dengan saliva sehingga terjadi penyerapan air ke dalam resin komposit. Penyerapan air pada resin komposit dapat menurunkan sifat fisis dan mekanis serta menimbulkan kelarutan elemen resin komposit sehingga akan memperpendek masa pakai dan menimbulkan toksis. Penelitian ini bertujuan untuk membandingkan besaran serapan air, kedalaman dan kecepatan penyerapan air antara resin komposit mikrohibrid dengan nanohibrid setelah direndam di dalam saliva buatan. Sampel yang digunakan pada penelitian ini dibuat dari resin komposit mikrohibrid dan nanohibrid berbentuk tablet berdiameter $15 \mathrm{~mm}$ dan tebal $1 \mathrm{~mm}$ dengan pengerasan sinar tampak biru. Penelitian dilakukan dengan merendam sampel di dalam saliva buatan selama 2, 4, 6, dan 8 jam. Besaran serapan air dihitung dari perubahan berat yang terjadi dan kedalaman penyerapan air diukur dengan menggunakan mikrograf mikroskop. Kecepatan penyerapan dihitung dengan membandingkan kedalaman penyerapan air dengan waktu perendaman. Hasil yang diperoleh memperlihatkan serapan air pada resin komposit mikrohibrid 2,69, 5,71, 5,88, dan 5,96\% sedangkan pada nanohibrid 5,34, 3,76, 3,09 dan 2,83\%. Hasil pengukuran kedalaman penyerapan air pada resin komposit mikrohibrid 3054,98, 6125,42, 8529,94, dan 8930,01 $\mu \mathrm{m}$ sedangkan pada nanohibrid 7830,77, 6941,29, 6844,67 dan 6120,53 $\mu \mathrm{m}$. Hasil penghitungan kecepatan penyerapan air resin komposit mikrohibrid adalah

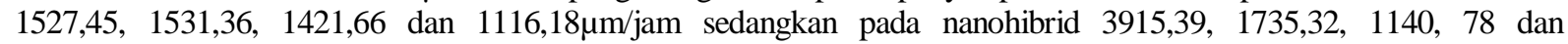


$761,32 \mu \mathrm{m} / \mathrm{jam}$. Analisis statistik menunjukkan perbedaan signifikan $(\mathrm{p} \leq 0,05)$ pada ketiga variabel tersebut antara kedua jenis resin komposit yang diuji. Dapat disimpulkan, serapan air dan kedalaman penyerapan resin komposit mikrohibrid lebih besar dibandingkan nanohibrid sedangkan kecepatan penyerapan air pada kedua jenis resin komposit mengalami penurunan

Kata kunci: resin komposit, mikrohibrid, nanohibrid, penyerapan air

\section{PENDAHULUAN}

Penggunaan bahan restorasi resin komposit di dalam mulut akan selalu berkontak dengan saliva. Resin komposit yang berkontak dengan air akan terjadi penyerapan air ke dalamnya. Penyerapan air merupakan salah satu sifat fisis yang dimiliki resin komposit karena resin komposit mengandung matriks resin yang bersifat hidrofilik..$^{1-5}$

Penyerapan air merupakan suatu fenomena yang berkelanjutan dan lama melalui proses difusi terkontrol. ${ }^{1-5}$ Penyerapan air pada resin komposit dipengaruhi oleh beberapa faktor antara lain, komposisi matriks resin, ukuran dan distribusi filler, dan derajat polimerisasi resin komposit. ${ }^{6}$ Penyerapan air yang terjadi akan menurunkan beberapa sifat resin komposit, seperti penurunan kekerasan, ketahanan terhadap keausan dan perubahan warna. Apabila resin komposit berkontak dengan air, beberapa elemen-elemen resin komposit, seperti monomer sisa, partikel filler, dan bahan lain dapat terlarut. Hal ini dapat menyebabkan alergi atau toksisitas terhadap tubuh. ${ }^{1-5}$

Penelitian untuk membuktikan penyerapan air pada resin komposit sudah banyak dilakukan dengan metode mengukur perubahan berat resin komposit setelah dilakukan perendaman dalam jangka waktu tertentu. Nayif dkk. menyatakan bahwa besarnya penyerapan air pada resin komposit tergantung pada waktu perendaman dan dipengaruhi oleh ukuran dan distribusi filler. ${ }^{7}$ Hegde dkk. membuktikan bahwa ukuran filler di dalam resin komposit menentukan tingkat penyerapan air pada resin komposit. ${ }^{8}$

Penelitian ini bertujuan untuk membandingkan besaran serapan air, kedalaman dan kecepatan penyerapan air antara resin komposit mikrohibrid dengan nanohibrid dan mengidentifikasi elemen yang terlarut setelah direndam di dalam saliva buatan. Pemakaian saliva buatan sebagai media perendam resin komposit lebih sesuai menggambarkan kondisi rongga mulut dan diharapkan dapat memberikan informasi yang lebih realistik mengenai fenomena penyerapan air pada resin komposit yang terjadi di dalam mulut.

\section{BAHAN DAN METODE}

Jenis penelitian adalah eksperimental laboratoris dengan desain penelitian (before-after design). Sampel pada penelitian ini adalah resin komposit mikrohibrid (Solare F, GC, Japan) dan nanohibrid (Brilliant G, Whaledent, Switzerland) dengan model induk dari logam yang berbentuk cincin dengan diameter $15 \mathrm{~mm}$ dan tebal $1 \mathrm{~mm}$. Jumlah sampel untuk tiap jenis resin komposit adalah 40 sampel, sehingga total sampel adalah 80 sampel.

Resin komposit dimasukkan kedalam model induk dan ditutup dengan cellophane strip dan diberi beban $1 \mathrm{~kg}$ selama 5 menit. Kemudian sampel disinar dengan sinar tampak biru (Litex A 680) selama 20 detik pada 5 titik yang berbeda. Sampel tiap-tiap resin komposit dibagi menjadi 4 kelompok perendaman di dalam saliva buatan yaitu 2, 4, 6, dan 8 jam. Masing-masing kelompok perendaman terdiri atas 10 sampel. Sampel ditimbang untuk mendapatkan berat awal (B0). Kemudian sampel direndam di dalam $5 \mathrm{ml}$ saliva buatan yang telah dicampur dengan $1 \mathrm{ml}$ gentian violet sebagai bahan pewarna dan disimpan di dalam inkubator $37^{\circ} \mathrm{C}$. Setelah waktu perendaman selesai, sampel dikeringkan dan ditimbang untuk mendapatkan berat akhir (B1).

Untuk mendapatkan nilai serapan air, dilakukan penghitungan dengan rumus B1-B0/B0 x 100\%. Setelah sampel ditimbang, permukaan atas dan bawah sampel dibuang menggunakan paper sand dengan grid 2000. Kemudian sampel diletakkan pada mikroskop mikrograf dengan pembesaran $40 \mathrm{X}$ untuk melihat kedalaman penyerapan air. Jarak penyerapan air dihitung dari tepi sampel sampai batas akhir warna ungu pada sampel. Pengukuran dilakukan pada 4 titik. Rerata hasil pengukuran kedalaman pada 4 titik tersebut ditetapkan sebagai nilai kedalaman penyerapan air pada sampel. Untuk kecepatan penyerapan air dihitung dengan membagi kedalaman penyerapan air dengan waktu perendaman.

Nilai rerata dan standar deviasi dianalisis dengan uji Kruskall-Wallis dan Mann-Whitney.

\section{HASIL}

Hasil penelitian menunjukkan rerata penyerapan air dari kelompok resin komposit mikrohibrid setelah direndam di dalam saliva buatan selama 2, 4, 6 dan 8 jam adalah $2,69 \pm 1,74 \% ; 5,71 \pm 3,33 \% ; 5,88$ $\pm 2,14 \%$ dan $5,96 \pm 2,74 \%$. Rerata serapan air resin komposit nanohibrid yang diperoleh setelah di- 
rendam di dalam saliva buatan selama 2, 4, 6, dan 8 jam adalah $5,34 \pm 0,29 \% ; 3,76 \pm 3,16 \% ; 3,09 \pm$ $1,67 \%$; dan $2,83 \pm 1,86 \%$ (Tabel 1).

Hasil uji analisis Kruskall-Wallis menunjukkan adanya perbedaan nilai serapan air yang signifikan antara resin komposit mikrohibrid dengan nanohibrid dengan nilai $\mathrm{p}<0,05$.

Tabel 1. Hasil analisis statistik nilai serapan air resin komposit mikrohibrid dan nanohibrid setelah perendaman

\begin{tabular}{cccc}
\hline Waktu & \multicolumn{2}{c}{ Rerata serapan air (\%) } & \\
\cline { 2 - 3 } $\begin{array}{c}\text { perendaman } \\
\text { (Jam) }\end{array}$ & $\begin{array}{c}\text { Resin komposit } \\
\text { mikrohibrid }\end{array}$ & $\begin{array}{c}\text { Resin komposit } \\
\text { nanohibrid }\end{array}$ & \\
\hline 2 & $2,69 \pm 1,74$ & $5,34 \pm 0,29$ & 0,002 \\
4 & $5,71 \pm 3,33$ & $3,76 \pm 3,16$ & \\
6 & $5,88 \pm 2,14$ & $3,09 \pm 1,67$ & \\
8 & $5,96 \pm 2,74$ & $2,83 \pm 1,86$ & \\
\hline
\end{tabular}

Rerata hasil pengukuran kedalaman penyerapan air resin komposit mikrohibrid setelah perendaman di dalam saliva buatan selama 2, 4, 6, dan 8 jam adalah $3054,98 \pm 1033,67 ; 6125,42 \pm 875,60$; $8529,94 \pm 2358,24$ dan 8930,01 $\pm 1142,46 \mu \mathrm{m}$. Untuk nilai kedalaman penyerapan air pada nanohibrid adalah $7830 \pm 1438,22 ; 6941,29 \pm 1695,88$; $6844,67 \pm 1512,68$ dan 6120,53 $\pm 1134,09 \mu \mathrm{m}$ (Tabel 2). Berdasarkan hasil analisis Kruskal-Wallis terdapat perbedaan kedalaman penyerapan air resin komposit mikrohibrid yang signifikan dengan nanohibrid $(\mathrm{p}<0,05)$.

Gambaran kedalaman penyerapan air pada resin komposit mikrohibrid dan nanohibrid menunjukkan adanya air yang terserap masuk ke dalam resin komposit (Gambar 1). Air yang masuk ditandai dengan warna ungu yang lebih tebal di sepanjang tepi sampel. Pada resin komposit mikrohibrid terlihat gambaran air yang masuk lebih dalam dibandingkan pada resin komposit nanohibrid.
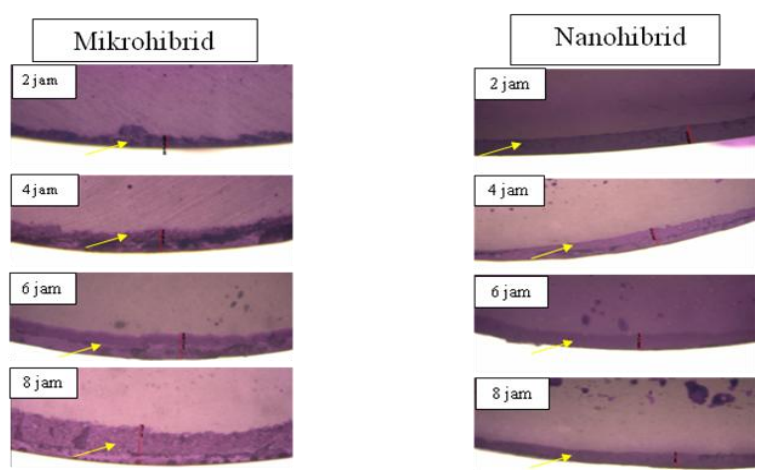

Gambar 1. Gambaran penyerapan air resin komposit mikrohibrid dan nanohibrid setelah perendaman di dalam saliva buatan selama 2, 4, 6, dan 8 jam.
Tabel 2. Hasil analisis statistik kedalaman penyerapan air resin komposit mikrohibrid dan nanohibrid setelah perendaman

\begin{tabular}{cccc}
\hline $\begin{array}{c}\text { Waktu } \\
\text { perendaman } \\
(\text { Jam })\end{array}$ & $\begin{array}{c}\text { Rerata kedalaman penyerapan air }(\mu \mathrm{m}) \\
\text { Resin komposit } \\
\text { mikrohibrid }\end{array}$ & $\begin{array}{c}\text { Resin komposit } \\
\text { nanohibrid }\end{array}$ & $\mathrm{p}$ \\
\hline 2 & $3054,98 \pm 1033,67$ & $7830,77 \pm 1438,22$ & 0,000 \\
4 & $6125,42 \pm 875,60$ & $6941,29 \pm 1695,88$ & \\
6 & $8529,94 \pm 2358,24$ & $6844,67 \pm 1512,68$ & \\
8 & $8930,01 \pm 1142,46$ & $6120,53 \pm 1134,09$ & \\
\hline
\end{tabular}

Rerata kecepatan penyerapan air resin komposit mikrohibrid setelah perendaman di dalam saliva buatan selama 2, 4, 6, dan 8 jam adalah 1527,45 \pm 525,$51 ; 1531,36 \pm 218,9 ; 1421,66 \pm 393,04$ dan $1116,18 \pm 142,71$. Sedangkan pada nanohibrid adalah $3915,39 \pm 719,11 ; 1735,32 \pm 423,97$; 1140,78 \pm 252,11dan 761,32 $\pm 143,95$ (Tabel 3). Hasil analisis Kruskall-Wallis menunjukkan terdapat perbedaan kecepatan penyerapan air yang signifikan mendapatkan $(p<0,05)$ antara resin komposit mikrohibrid dengan nanohibrid.

Tabel 3. Hasil analisis statistik kecepatan penyerapan air resin komposit mikrohibrid dan nanohibrid setelah perendaman

\begin{tabular}{|c|c|c|c|}
\hline \multirow{2}{*}{$\begin{array}{c}\text { Waktu } \\
\text { perendaman } \\
\text { (Jam) }\end{array}$} & \multicolumn{2}{|c|}{$\begin{array}{l}\text { Rerata kecepatan penyerapan air } \\
(\mu \mathrm{m} / \mathrm{jam})\end{array}$} & \multirow{2}{*}{$\mathrm{p}$} \\
\hline & $\begin{array}{l}\text { Resin komposit } \\
\text { mikrohibrid }\end{array}$ & $\begin{array}{l}\text { Resin komposit } \\
\text { nanohibrid }\end{array}$ & \\
\hline 2 & $1527,45 \pm 525,51$ & $3915,39 \pm 719,11$ & 0,000 \\
\hline 4 & $1531,36 \pm 218,9$ & $1735,32 \pm 423,97$ & \\
\hline 6 & $1421,66 \pm 393,04$ & $1140,78 \pm 252,11$ & \\
\hline 8 & $1116,18 \pm 142,71$ & $761,32 \pm 143,95$ & \\
\hline
\end{tabular}

\section{PEMBAHASAN}

Hasil penelitian menunjukkan besaran serapan air yang terkecil pada resin komposit mikrohibrid adalah pada perendaman 2 jam (2,69\%) sedangkan yang terbesar adalah pada perendaman 8 jam (5,96\%). Pada resin komposit nanohibrid besaran serapan air yang terkecil adalah pada perendaman 8 jam $(2,83 \%)$ dan yang terbesar pada perendaman 2 jam $(5,34 \%)$. Hal ini juga terlihat pada hasil kedalaman penyerapan air yang diperoleh, yaitu kedalaman penyerapan air resin komposit mikrohibrid yang terkecil adalah pada perendaman 2 jam $(3054,98 \mu \mathrm{m})$ dan yang terbesar pada perendaman 8 jam $(8930,01 \mu \mathrm{m})$. Sementara kedalaman penyerapan air resin komposit nanohibrid yang terkecil pada perendaman 8 jam $(6120,53 \mu \mathrm{m})$ dan yang terbesar pada perendaman 2 jam $(7830,77 \mu \mathrm{m})$. Hal ini memperlihatkan bahwa perendaman resin komposit mikrohibrid di dalam saliva buatan selama 2, 4, 6, dan 8 jam menyebabkan peningkatan besaran serap- 
an air dan kedalaman penyerapan air sedangkan resin komposit nanohibrid menunjukkan penurunan besaran serapan air dan kedalaman penyerapan air. Pada penelitian ini, kecepatan penyerapan air menunjukkan penurunan pada kedua jenis resin komposit yang diuji sesuai bertambahnya waktu perendaman. Berdasarkan hasil analisis KruskalWallis, ketiga variabel yang diuji menunjukkan perbedaan yang signifikan diantara resin komposit mikrohibrid dengan nanohibrid $(\mathrm{p}<0,05)$.

Resin komposit mikrohibrid yang digunakan pada penelitian ini mengandung partikel filler sebanyak $30-40 \%$ volume dengan ukuran partikel filler berkisar 0,2-3 $\mu \mathrm{m}$ sedangkan resin komposit nanohibrid mengandung partikel filler sebanyak $65 \%$ volume dengan ukuran partikel filler berkisar 0,012,5 $\mu \mathrm{m}$. Penyerapan air resin komposit mikrohibrid lebih besar dibandingkan resin komposit nanohibrid kemungkinan disebabkan ukuran partikel filler dan jumlah filler yang berbeda antara resin komposit mikrohibrid dan nanohibrid. Hasil penelitian ini menunjukkan hal yang sama dengan penelitian Mayform dkk. yang mendapatkan penyerapan air yang lebih besar pada resin komposit yang mengandung 59,5\% filler dibandingkan dengan $60 \%$ filler. $^{9}$

Beberapa penelitian lain seperti Hegde dkk. mendapatkan penyerapan air pada resin komposit microfinehybrid lebih besar dibandingkan resin komposit nanofiller pada minggu pertama dan menurun secara bertahap pada minggu berikutnya setelah direndam di dalam air destilasi selama 6 minggu. ${ }^{8}$ Berger dkk. di dalam penelitiannya menemukan penyerapan air pada resin komposit microfiller lebih besar dibandingkan resin komposit minifiller dan nanofiller setelah direndam di dalam air selama 7 hari. ${ }^{10}$

Jumlah filler di dalam resin komposit dapat mempengaruhi penyerapan air dan kelarutan, hal ini mungkin berkaitan dengan proporsi filler resin yang mengurangi volume resin. ${ }^{8}$ Peningkatan jumlah partikel filler dapat menurunkan penyerapan air ke dalam resin komposit. Selain itu, ukuran partikel filler yang ditambahkan ke dalam resin komposit juga dapat mempengaruhi penyerapan air ke dalam resin komposit. Resin komposit yang mengandung partikel filler lebih kecil memiliki nilai penyerapan air lebih rendah. ${ }^{1-5}$

Pada penelitian ini, penyinaran dilakukan dengan waktu penyinaran 20 detik dan jarak penyinaran 2 mm dengan arah sinar tegak lurus. Penyinaran dilakukan pada 5 titik pada permukaan atas sampel, yaitu di tengah, atas, bawah, samping kiri dan kanan. Hal ini dilakukan karena ukuran diameter sampel lebih besar dari diameter ujung alat sinar, se- hingga diharapkan polimerisasi yang adekuat dapat terjadi pada semua bagian dari sampel. Menurut Ferracane kedalaman dan kecepatan penyerapan air tergantung pada kepadatan polimer, potensial ikatan hidrogen dan interaksi polar. Kualitas jaringan polimer pada resin komposit terbentuk selama proses polimerisasi. Resin komposit yang memiliki kepadatan cross-linking yang tinggi akan mengurangi penyerapan air, karena ikatan kovalen pada crosslinking mempertahankan kedekatan cincin-cincin polimer. ${ }^{6}$ Proses polimerisasi yang adekuat dipengaruhi oleh lama penyinaran, jarak penyinaran, jenis sinar, kedalaman penyinaran, dan metode polimerisasi. ${ }^{1-3}$ Penelitian da Silva dkk. mendapatkan penyerapan air dan kelarutan pada resin komposit yang disinar dengan metode penyinaran konvensional lebih rendah dibandingkan dengan metode penyinaran soft-start. Penyerapan air dan kelarutan pada resin komposit nanofiller lebih tinggi dibandingkan resin komposit midifiller yang direndam di dalam saliva buatan, asam laktat dan air destilasi. Hal ini disebabkan karena resin komposit nanofiller memiliki derajat konversi lebih rendah yaitu $55,7 \pm 3,8 \%$ dibandingkan resin komposit midifiller sekitar $59,0 \pm 4,6 \%{ }^{11}$

Berdasarkan hasil penelitian yang diperoleh dapat disimpulkan bahwa nilai serapan air dan kedalaman penyerapan air pada bahan restorasi resin komposit mikrohibrid lebih besar dibandingkan resin komposit nanohibrid setelah direndam di dalam saliva buatan selama 2, 4, 6, dan 8 jam. Akan tetapi kecepatan penyerapan air pada kedua jenis resin mengalami penurunan seiring bertambahnya waktu perendaman.

\section{Daftar Pustaka}

1. O'brien WJ. Dental materials and their selection. 3rd ed. Chicago: Quintessence Publishing Co., 2002: 113-18.

2. Anusavice KJ. Phillip's science of dental materials. $11^{\text {th }}$ ed., St.Louis: Elsevier., 2008: 399-437.

3. Van Noort R. Introduction to dental materials. 3rd ed. St.Louis: Mosby Elsevier., 2008: 99-123.

4. Gladwin M, Bagby M. Clinical aspects of dental materials theory, practice and cases. 3rd ed. Philadelphia: Wolters Kluwer., 2009: 60-5.

5. Sakaguchi RL, Power JM. Craig's restorative dental materials. $13^{\text {th }}$ ed., Philadelphia: Mosby Elsevier., 2012: 162-91.

6. Ferracane JL. Hygroscopic and hydrolytic effects in dental polymer networks. Dental Materials 2006; 22: 211-22.

7. Nayif MM, Suliman AA, Nikaido T, Ikeda M, Foxton RM, Tagami J. Long-Term water absorption of three resin based restorative materials. Int Chin J Dent 2005; 5: 1-6. 
8. Hegde MN, Biradar B. Evaluation of weight change in three different light cured composite restorative materials stored in water: an invitro study. J Conserv Dent 2008;11(3): 108-11.

9. Mayform CD, da Rocha-Leao MHM, Bastian FL. Artificial saliva absorption of two hybrid nanoparticle resin based restorative dental composites. In: 2nd Mercosur Congress on Chemical Engineering and 4th Mercosur Congress on Process Systems Engineering in Brasil, 2005.
10. Berger SB, Palialol ARM, Cavalli V, Giannini M. Characterization of water absorption, solubility and filler particles of light-cured composite resin. Braz Dent J 2009; 20(4): 314-8.

11. da Silva EM, Almeida GS, Poskus LT, Guimaraes JGA. Relationship between the degree of conversion, solubility and salivary absorption of a hybrid and a nanofilled resin composite: Influence of the light-activation mode. J Appl Oral Sci $2008 ; 16(2)$. 